Т. А. Полякова преподаватель

\title{
ТЕРМИНОЛОГИЯ МАРКЕТИНГА В РУССКОМ ЯЗЫКЕ: ТЕРМИНОЛОГИЧЕСКИЕ ЗАИМСТВОВАНИЯ
}

Статтю присвячено питанню формування терміносистеми маркетингу в сучасній російській мові.

В этой статье речь пойдет о конкретной современной экономической науке - маркетинге и о терминосфере маркетинга, которая складывается по образцу западноевропейских, англо-американских, германских терминосистем. Терминология маркетинга русского языка активно и динамично реагирует на все социальные запросы переводческой и лексикографической практики, поэтому часто выступает в качестве терминосистемыпосредника. Новейшие заимствования поступают в русские терминосистемы непосредственно из языка-носителя.

Доминантным фактором, вызывающим активные заимствования иноязычной терминологии на современном этапе в русском языке, является 
этап формирования понятийного пространства различных сфер рыночной экономики в русскоязычных странах. 70\% терминов в терминосистеме маркетинга заимствованы из английского языка и его американского варианта, $30 \%$ составляет заимствование из других языков. Терминологические заимствования в наши дни (термины и кальки) входят в принимающие системы не разрозненными единицами, а группами и целыми тематическими блоками $[8,38]$.

Во-первых, это связано с тем, что сложившаяся иноязычная терминосистема маркетинга «предлагает» узуальные обозначения, которым не всегда можно найти однословный эквивалент.

Во-вторых, существенную роль играет влияние иноязычной концептосферы маркетинга на соответствующие концептосферы русского языка, когда вместе с соответствующим концептами заимствуются и их прямые или калькированные обозначения. Этим обусловливается такая черта современного процесса терминологического заимствования, как заимствование терминов вместе с заимствованием новых явлений, понятий, реалий.

Данное явление всегда было присуще процессу заимствования, но в настоящее время отмечается его особая роль в формировании отдельных терминосистем, в частности терминосистемы маркетинга. Чаще всего, как мы уже отмечали, новому понятию невозможно найти оптимальный эквивалент. Так, например, в наши дни входит в употребление термин «коммуникация». В иноязычной графике этот термин дается как Communication связь, сообщение; средство связи, сообщения; коммуникационные линии (от латинского «Communicatio», «Communico» - связываюсь, общаюсь).

Объективная необходимость использования понятия «коммуникация» для характеристики информационных процессов в обществе обусловлена социальными этапами развития рыночных отношений, которые расширяют сферу его использования. Существуют несколько значений термина «коммуникация», зависящих от цели, поставленной исследователями. Анализ использования этого слова дает возможность определить структуру классификации термина, а также подходы к его изучению.

Пути обозначения понятия «Коммуникация»:

- лингвистический;

- философский;

- психологический;

- социальный;

- экономический.

Как видим из перечисленного, на первом месте стоит «лингвистический» подход к понятию термина «коммуникация» $[6,40]$.

Различают два аспекта «коммуникации»:

- физическая (ФК);

- социальная (СК). 
Физическая коммуникация - способ передачи информации от одного источника к другому.

Социальная коммуникация - конкретный аспект социального взаимодействия: двусторонний или многосторонний процесс образования и развития контактов между людьми, которые обусловливают их потребности в совместной деятельности.

Некоторые авторы полагают, что коммуникация - это процесс сообщения между пунктами назначения, а средства связи являются коммуникационными каналами передачи.

Другие ученые [4, 73] рассматривают коммуникацию как процесс (трансформирования, передачи-трансформации) информации с использованием слов, букв, символов либо аналогичных способов для получения общей или частной информации об объекте или действии.

Для четкого обозначения они распределяют термины:

- семантика коммуникаций - значение слов и символов;

- синтаксис коммуникаций - взаимосвязь символов, которыми пользуются;

- прагматика коммуникаций - результативность и эффективность при достижении определенных целей.

Существуют шесть основных приемов маркетинговых коммуникаций (MK):

1) реклама - платная форма информации;

2) персональная продажа - без посредников;

3) стимулирование сбыта - целевая направленность на сбыт товаров;

4) пропаганда - бесплатная форма передачи информации;

5) паблик рилейшинз - любая форма воздействия информации на общество с целью формирования положительного отношения к фирме, деятельности и товарам, которые она выпускает с помощью массовой информации;

6) Директ маркетинг (от англ. «direct» - прямой, прямо; непосредственно; «marketing» - маркетинг от «market» - рынок, сбывать, продавать или покупать на рынке) - платная форма особой информации непосредственно на получателя или партнера конкретно адресованному с целью покупки товара и т. д.

Рассмотрим последний термин маркетинговых коммуникаций - паблик рилейшинз, который происходит от английских слов «public»- (народ, широкая публика, общественность) и «relation»- повествование, отношение, связь.

Термин «паблик рилейшинз» пока не зафиксирован словарями современного русского языка. Его используют в значении «связь как с населением, так и общественными отношениями».

Часто этот термин интерпретируют в русском языке как «сторонние отношения» или «общественные связи» - близкие по смыслу. 
Нередко появление заимствованного слова связано с необходимостью в разграничении и специализации понятий. В последние годы в терминосфере маркетинга появляются и закрепляются термины англоамериканского происхождения:

- «масс-медиа» от «Mass» (собирать в кучу, в массу, концентрировать), «media» от «medium» (средство, способ, средний, промежуточный). В маркетинговых коммуникациях это трактуется как фирменные печатные периодические издания;

- «Receiver»- получатель, адресат.

Также заслуживающими внимания представляются определениясинонимы термина «комплекс маркетинг»:

- структура маркетинга;

- маркетинг-микс (от англ. «тіх» - смесь, смешивать);

- функция 4p (от англ. четыре английских [рі:] - математическое определение зависимости результата от успеха рыночной деятельности (функции) от четырех указанных выше переменных аргументов; в английском языке все они начинаются с буквы «Р»: товар - «product» (goods), цена «price», сбыт - «plase», «phisial distribution», продвижение - «promotion».

Как видим, в области расширения терминосферы появился такой фактор, как стремление к более современному термину. Это приводит зачастую к предпочтению иноязычного (чаще англоязычного) термина даже при наличии уже существующего слова.

Анализ данного материала показывает, что пласт новой терминологической лексики маркетинга представляет заимствования из английского языка. Для обозначения заимствований из английского языка в современной лингвистической литературе все чаще встречаются термин «англицизм», который в некоторой степени понимается как равнозначный термину «заимствованное слово».

Понятие англоязычного заимствования не исчерпывает заимствованных слов. Существуют проблемы классификации заимствованных слов, интернационализации терминологии и языковой политики.

\section{Список использованной литературы}

1. Гончарук Я. А., Павленко А. Ф., Скибинский С. В. Маркетинг. Навч. пос. - К., 2004. - $392 \mathrm{c}$.

2. Жданова И. Ф. Краткий русско-коммерческий словарь. - М., 1991. -175 с.

3. Международный кодекс рекламной практики. / Перевод Генина Н. В., Демидова В. Е. - К.: Реклама, 1995. - 156 с.

4. Мюллер В. К. Англо-русский словарь - М.: Изд-во «Русский язык», 1981. - 884 с.

5. Помат Е. Реклама. - К.-Х.: НВФ - «Студцентр», 2000. - 476 с.

6. Примак Т. О. Маркетингові комунікації. - К., 2003. - 198 с.

7. Примак Т. О. Рекламный креатив. Навч. пос. - К., 2006. -325 с.

8. Пристайко Т. С. Лексико-номинативная организация специального текста. Монография. - Днепропетровск: «УКО-ІМА-прес», 1996. - 200 с. 
9. Смешко А. П. Англо-русский разговорник. - К.: «Предприятие Колос», 1992. $-113 \mathrm{c}$.

10. Смешко А. П. Глоссарий - спутник бизнесмена. - К.: «Предприятие Колос», 1992. - $113 \mathrm{c}$.

11. Смешко А. П. Деловая переписка. - К.: «Предприятие Колос», 1992. - 123 с.

12. Советский энциклопедический словарь / Под ред. Прохорова А. М. - М.: «Советская энциклопедия», 1981. - 1600 с.

\section{Summary}

The article deals with the problem of marketing terminology in the Russian language. Its borrowings from English and its American variant. 